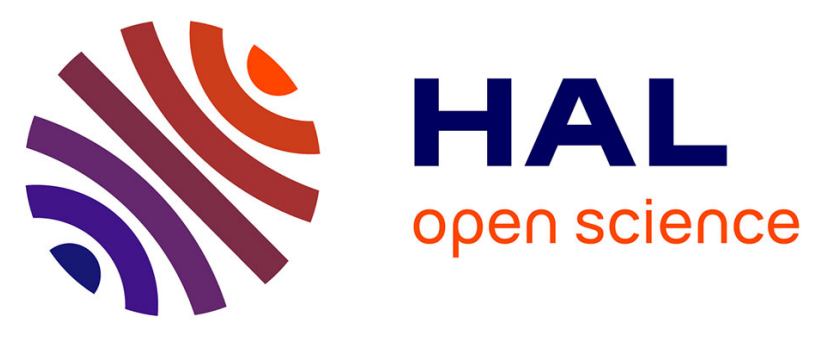

\title{
Light-Responsive Pyrazine-Based Systems Probing Aromatic Diarylethene Photocyclization
}

\author{
Jovana V. Milic, Cedric Schaack, Nora Hellou, Florin Isenrich, Renana \\ Gershoni-Poranne, Dmytro Neshchadin, Sylvain Egloff, Nils Trapp, Laurent \\ Ruhlmann, Corinne Boudon, et al.
}

\section{To cite this version:}

Jovana V. Milic, Cedric Schaack, Nora Hellou, Florin Isenrich, Renana Gershoni-Poranne, et al.. Light-Responsive Pyrazine-Based Systems Probing Aromatic Diarylethene Photocyclization. Journal of Physical Chemistry C, 2018, 122 (33), pp.19100-19109. 10.1021/acs.jpcc.8b05019 . hal-01879770

\section{HAL Id: hal-01879770 \\ https://hal-univ-rennes1.archives-ouvertes.fr/hal-01879770}

Submitted on 28 Sep 2018

HAL is a multi-disciplinary open access archive for the deposit and dissemination of scientific research documents, whether they are published or not. The documents may come from teaching and research institutions in France or abroad, or from public or private research centers.
L'archive ouverte pluridisciplinaire HAL, est destinée au dépôt et à la diffusion de documents scientifiques de niveau recherche, publiés ou non, émanant des établissements d'enseignement et de recherche français ou étrangers, des laboratoires publics ou privés. 


\section{Light-Responsive Pyrazine-Based Systems: Probing Aromatic Diarylethene Photocyclization}

Jovana Milicis ${ }^{\S}$, Cédric Schaack $^{\S \sharp}$, Nora Hellou ${ }^{\dagger}$, Florin Isenrich $^{\S}$, Renana Gershoni-Poranne ${ }^{\S}$, Dmytro Neshchadin ${ }^{\ddagger}$, Sylvain Egloff , Nils Trapp ${ }^{\S}$, Laurent Ruhlmann ", Corinne Boudon ", Georg Gescheidt ${ }^{\ddagger}$, Jeanne Crassous ${ }^{\dagger}$, François Diederich ${ }^{{ }^{*}}$

${ }^{\S}$ Laboratory of Organic Chemistry, ETH Zurich, Vladimir-Prelog-Weg 3, 8093 Zurich, Switzerland. ${ }^{\dagger}$ Institut des Sciences Chimiques de Rennes, UMR 6226, CNRS Université de Rennes 1, Campus de Beaulieu, 35042 Rennes Cedex, France. ${ }^{\ddagger}$ Institute of Phyiscal and Theoretical Chemistry, Graz University of Technology, Stremayrgasse 9/Z2, 8010 Graz, Austria.

"Université de Strasbourg, Laboratoire d'Électrochimie et Chimie Physique du Corps Solide, Institut de Chimie de Strasbourg, 4 rue Blaise Pascal - CS 90032, 67081 Strasbourg, France. \# Authors have contributed equally to this work.

ABSTRACT. We present an investigation of the photocyclization of novel aromatic diarylethene (DAE) systems 1-3 based on pyrazine, quinoxaline, and helicene scaffolds. These prospective photoswitches were designed using DFT calculations and analyzed in solution and in the solid state by cyclic and rotating disc voltammetry, UV-Vis and transient absorption spectroscopy, as well as X-ray crystallography. Additionally, Nucleus Independent Chemical Shift (NICS) calculations were performed to investigate the influence of the aromaticity on the photocyclization ability. While pyrazine-2,3-diyl-extended DAE system 1 demonstrated photoswitching ability with short lifetimes of the cyclized form, the more aromatic quinoxaline analogue $\mathbf{2}$ did not feature any photocyclization. Further extension of these aromatic systems into helicene-DAE $\mathbf{3}$ resulted in stabilization of the cyclized form through the conserved backbone aromaticity, accompanied by 
enhanced photochromism. This study paves the way toward the generation of aromatic DAE photoswitches for light-controlled molecular systems in the future.

\section{INTRODUCTION}

Modulating the function of nanosystems by light is an appealing challenge, since light is a noninvasive external stimulus that provides high spatiotemporal resolution to alter conformational and electronic properties. ${ }^{1-3}$ Light-controlled molecular machinery requires installation of a suitable photo-sensitive moiety within its scaffold. ${ }^{3}$ Diarylethenes (DAE) are efficient, versatile photoswitches that can be used to control the properties of functional molecular materials by light. ${ }^{4-}$

${ }^{9}$ The photoswitchable DAE unit consists of an olefinic linker substituted by two aromatic moieties, commonly thiophenes. ${ }^{5,10}$ Upon exposure to UV light, the open form undergoes a $6 \pi$ electrocyclization to the closed form. Irradiation of the closed form with visible light yields the reverse reaction, resulting in an opening of the DAE core (Scheme 1a). DAE photoswitches are particularly attractive owing to their high fatigue resistance, providing a remarkable reversibility of the photocyclization. ${ }^{10,11}$ Moreover, the cyclized form exhibits enhanced conjugation, which alters the optoelectronic properties of the switch and results in a shift of the lowest-energy electronic absorption band towards the visible range, rendering DAE systems photochromic.

\section{Scheme 1}

DAE photoswitches based on $\pi$-linkers that are part of an aromatic ring (such as $\mathbf{4}$, Scheme 1 b) are highly desirable for the functionalization of complex molecular materials, ${ }^{15-18}$ but remain scarcely investigated. ${ }^{19-21}$ Aromatic DAEs containing phenanthrene ${ }^{13,22}$ and phenanthroline $e^{14,15,23}$ moieties, which were developed by Walko and Feringa $(\mathbf{5})^{13}$ or Yam et al. $(\mathbf{6}),{ }^{14}$ were shown to operate under similar conditions to conventional DAE switches (Scheme 1c), while effectively 
mimicking olefinic systems in accordance with Clar's rule of $\pi$-sextets, leaving the central core of these systems with lower aromatic delocalization of the electron density (Scheme 1c). ${ }^{24-26}$ In contrast, the phenyl-DAE systems are not reported to photocyclize (Scheme $1 \mathrm{~b}){ }^{12}$ possibly due to the fact that this system is more aromatic and therefore 'resistant' to photocyclization. Specifically, introducing an aromatic ring as a DAE linker is likely to decrease the photocyclization efficiency due to aromatic $\pi$-bond delocalization and the aromatic stabilization energy (ASE). As a result, the activation barrier for the reverse reaction decreases owing to a higher gain in energy for the rearomatization upon ring opening, leading to a favorable thermal ring-opening reaction. In this regard, assuming that the ASE of aromatic DAE switches plays a major role in their ability to photocyclize, we investigated the new series 1-3 for their propensity to undergo photocyclization (Figure 1). We envisioned that systems with attenuated aromaticity would feature higher photocyclization efficiency, since the loss of ASE upon photocyclization would be reduced, which corresponds to a decrease in energy gain for the reverse reaction. According to this rationale, the design of pyrazine-DAE 1 was based on lowering the ASE by introducing heteroatoms, such as nitrogen, to improve the photocyclization ability. ${ }^{24,27-30}$ Extension of this pyrazine core in order to match the electronic and structural properties of traditional DAE photoswitches led to the development of quinoxaline-DAE 2 and diaza[5]helicene-DAE 3 . While the quinoxaline derivative 2 was equipped with electron-withdrawing fluorine groups to improve its photochromic features, ${ }^{11}$ the pentahelicene structure of $\mathbf{3}$ was assumed to stabilize the cyclic form due to the stabilization of the backbone $\pi$-system, which was assessed by DFT calculations. The optoelectronic properties of these DAEs were investigated by cyclic $(\mathrm{CV})$ and rotating disc voltammetry (RDV), UV-Vis, and transient absorption spectroscopy, aimed at probing the effect 
of aromaticity on the photocyclization and identifying design principles for aromatic DAE photoswitches.

\section{Figure 1}

\section{RESULTS AND DISCUSSION}

Synthesis. The DAE systems 1-3 were prepared through condensation of the bisthiophene dione 7 with suitable diamino precursors (Scheme 2a). Accordingly, ethane-1,2-diamine was employed to access precursor $\mathbf{8}$ (Scheme $2 \mathrm{~b}$ ), which was oxidized on air to afford pyrazine-DAE $\mathbf{1}$ (Scheme 2c). Similarly, 4,5-difluorobenzene-1,2-diamine was used to prepare quinoxaline derivative 2 (Scheme 2d), whereas helicene diamine $\mathbf{9}^{31}$ was required to produce helicene $\mathbf{3}$ (Scheme 2e). The dione precursor 7 was synthesized by Lewis-acid catalyzed Friedel-Crafts acylation of 2,5dimethylthiophene with oxalyl chloride. ${ }^{32}$

\section{Scheme 2}

Geometry Analysis. The geometry of the DAE switches determines their photocyclization ability in accordance with the Woodward-Hoffmann rules, which require an antiparallel conformation for the $6 \pi$-conrotatory photocyclization to take place. ${ }^{5,10}$ The conformational preference of DAE systems 1-3 was thereby analyzed in the gas phase, solution, and solid state by means of DFT calculations,${ }^{33-34}{ }^{1} \mathrm{H}$ NMR spectroscopy, and X-ray crystallography (Figure 2; for further details, see Sections S2-S3 and S7 of the Supporting Information (SI)).

\section{Figure 2}

DFT calculations at the B3LYP/6-31G(d) level of theory of pyrazine-DAE 1 in the gas phase suggested that parallel and antiparallel conformations are likely to interconvert at ambient temperature due to low energy barriers for interconversion (for details, see Section S7 in the SI). 
Barriers for exchange to the antiparallel conformation in solution are low and the desired geometry for photocyclization is readily attained. ${ }^{5,10}$ In the crystal structure, however, pyrazine-DAE $\mathbf{1}$ and quinoxaline-DAE 2 adopt a parallel conformation, with two thiophene rings oriented parallel and methyl groups pointing in the same direction, which prevents photocyclization in the solid state owing to a $180^{\circ}$ twist of one of the thiophene units, which hampers the orbital interaction for $6 \pi$ electrocyclization (Figure 2). On the other hand, helicene-DAE $\mathbf{3}$ crystallized in the antiparallel conformation, with a distance of 3.4 A between the two thiophene carbon centers undergoing bond formation during electrocyclization, which could potentially allow for its photocyclization to occur in both solution and the solid state. ${ }^{10}$ Cyclization attempts in the solid state were therefore performed using various medium-pressure mercury lamps and repeatedly yielded the open-form helicene-DAE 3 under these conditions. The feasibility of the cyclization process was further assessed by probing the aromaticity of the DAE systems.

Evaluation of Aromaticity. Photocyclization of an aromatic DAE system to the closed form of the photoswitch can result in loss of aromaticity (Scheme 1b), favoring the reverse reaction due to a higher energy loss gain upon re-aromatization. Therefore, this process is expected to occur more readily in systems with lower ASE. ${ }^{13-15,19-20,35}$ A common way to probe the magnetic criterion of aromaticity of a given compound is with the Nucleus Independent Chemical Shifts (NICS) computational method..$^{24,27-30}$ NICS probes report the chemical shift of any point in space at which they are placed. For evaluating aromaticity, the probes are traditionally placed at the center of a cycle of interest, at a height of $1 \AA$ above the molecular plane. The NICS values are indicative of the strength of the induced magnetic field that arises from the induced ring current sustained by aromatic systems when placed into an external magnetic field (most commonly calculated with the gauge-including atomic orbital (GIAO) method). In this regard, negative NICS values indicate a 
diatropic ring current, which usually corresponds to an aromatic system, while positive values indicate a paratropic ring current, which generally corresponds to the system being anti-aromatic. ${ }^{27}$ By comparing the NICS values of various systems, it is possible to generate a scale of aromaticity, where more negative values indicate that the system is more aromatic. ${ }^{27}$ DFT calculations of the NICS $(1)_{\pi Z Z}$ values at B3LYP/6-311+G(d) were performed, using the NICS-Scan methodology and the $\sigma$-Only Model, as implemented in the Aroma software package. ${ }^{29-30}$ These ensure that the values obtained reflect only the contributions of the $\pi$-electrons to the ring current and have been shown to produce more physically relevant results (for details and complementary NICS-XYScans ${ }^{28}$ see Section S7 in the SI). We first compared the aromaticity of DAEs 1-3 (Figure 3a) to those systems with precedence in the literature (e.g. 4-6, Figure 3b). The central rings of the starting materials demonstrate comparable NICS $(1)_{\pi Z z}$ values indicating a relatively high degree of aromaticity (for comparison, the NICS(1) $)_{\pi z z}$ value of benzene at the same level of theory is -34 $\mathrm{ppm}$ ), whereas the same rings display different values after the cyclization, ranging from $3 \mathrm{ppm}$ (which may be interpreted as non-aromatic) for systems 4-6 to up to $30 \mathrm{ppm}$ for quinoxaline $\mathbf{3}$ (which indicates significant paratropic currents; for comparison, cyclobutadiene at the same level of theory has a NICS(1) $)_{\pi Z z}$ value of $\left.\sim 42 \mathrm{ppm}\right){ }^{29-30}$ We can further identify that systems $\mathbf{3}, \mathbf{5}$, and $\mathbf{6}$ retain aromatic moieties within the larger molecular structures upon cyclization, while systems $\mathbf{1}$, 2, and 4 lose all diatropic ring currents, and thus, presumably, their aromaticity (Figure 3; for details, see Section S7 in the SI). If indeed the aromaticity is the major effect governing the cyclization, the former systems are expected to be more suitable switches as the latter systems should resist cyclization. 
In order to provide further insights to this question, we probed the photochemical properties and the photocyclization ability experimentally by means of cyclic (CV) and rotating disc voltammetry (RDV), as well as UV-Vis and transient absorption spectroscopy.

\section{Figure 3}

Electrochemisty. Electronic properties of DAEs 1-3 were evaluated by CV and RDV on glassy carbon (GC) electrodes (Figure 4). The $\mathrm{CV}$ of 1 in $\mathrm{CH}_{3} \mathrm{CN}\left(+0.1 \mathrm{M} n-\mathrm{Bu}_{4} \mathrm{NBF}_{4}\right)$ displays a single oxidation peak at $+1.23 \mathrm{~V}\left(\mathrm{vs} \mathrm{Fc}^{+} / \mathrm{Fc}\right.$; Figure $4 \mathrm{a}$, all redox potentials in the manuscript refer to this couple), which corresponds to the formation of the thiophene radical cation characteristic for systems with thiophene substituents as $\pi$-donating groups. ${ }^{36}$ The anodic shift of the oxidation potential of the thiophene in pyrazine-DAE 1 compared to the values characteristic for arylthiophenes (ca. +0.8-0.9 V) ${ }^{11,36-37}$ suggests donor-acceptor character, which has been shown to play a substantial role in the behavior of conventional DAE photoswitches. ${ }^{5,10}$ Extended aromatic systems $\mathbf{2}$ and $\mathbf{3}$ also feature an anodic shift with two successive irreversible oxidations at $+1.05 \mathrm{~V}$ and $+1.29 \mathrm{~V}$ for $\mathbf{2}$ and $+0.97 \mathrm{~V}$ and $+1.27 \mathrm{~V}$ for $\mathbf{3}$, respectively. Additionally, their CVs show a quasi-reversible quinoxaline reduction wave that appears at $-2.05 \mathrm{~V}$ for quinoxaline-DAE 2 (Figure S15 in the SI) and -1.9 V for helicene 3 (Figure 4b; for details, see Section S4 in the SI), which is cathodically shifted as compared to the reduction potentials of reference aryl-quinoxaline systems that do not feature significant donor-acceptor character (for instance, ca. $-1.70 \mathrm{~V}$ for thiophene quinoxaline systems). ${ }^{36-37}$ These redox interconversions were confirmed by RDV (for details, see Section S4 in the SI). Moreover, irradiation of the solutions of $\mathbf{1}-\mathbf{3}$ by intense white light using $300 \mathrm{~W}$ Arc Xe lamp altered the CV profiles. This was particularly notable for helicene 3 (Figure 4b; red line), indicating possible light-induced transformations that were assumed to be 
associated with the photocyclization. In order to interpret the nature of this response to irradiation, the donor-acceptor properties of $\mathbf{1 - 3}$ indicated by CV and RDV were further evaluated by UV-Vis spectroscopy in conjunction with DFT calculations.

\section{Figure 4}

Photochemical Properties. The donor-acceptor character of DAE systems 1-3 can affect their photocyclization ability. Further investigations by DFT calculations at the B3LYP/6-31G(d) level

of theory using Gaussian program ${ }^{33-34}$ revealed an increase in dipole moment along the central molecular axis $(\mu / \mathrm{D})$ from 0.42 for $\mathbf{2}$, through 0.76 for $\mathbf{3}$, to 1.31 for the directly substituted pyrazine-DAE 1, in line with the increase in donor-acceptor character (for details, see Section S7 in the SI). This was further supported by the calculated UV-Vis spectra (TD-DFT:CAM-B3LYP/6$31 \mathrm{G}(\mathrm{d})$ level of theory in $\mathrm{CH}_{3} \mathrm{CN}$ by using a polarizable continuum solvation model (PCM) of the Gaussian program $;{ }^{33-34}$ see Section 7 in the SI for further details $)$, which revealed the CT band $\left(\lambda_{\max }\right.$ $=290 \mathrm{~nm}$ ) attributed to the HOMO $\rightarrow$ LUMO transitions. This is also evident when analyzing the Frontier Molecular Orbitals (FMOs, Figures 5a,c; more details are provided within Section S7 in the SI). In the HOMO, the electron density is evenly distributed throughout the thiophene rings of 1-3, while this trend is inverted in the LUMO with the electron density distribution predominantly occupying the pyrazine core and aromatic backbone. The predicted UV-Vis spectra of the open forms of 1-3 feature two absorption maxima between $270 \mathrm{~nm}$ and $290 \mathrm{~nm}$ (Figures $5 \mathrm{~b}$,d; for details, see Section S7 in the SI). On the contrary, the closed forms of $\mathbf{1}-\mathbf{3}$ were predicted to display new, red-shifted absorption bands, as a result of the delocalization of the electron density through the $\pi$-systems in the closed state (Figures $5 \mathrm{~b}, \mathrm{~d}$; red spectrum). ${ }^{5,10}$

\section{Figure 5}


The optoelectronic properties of the open states were further investigated experimentally by means of UV-Vis spectroscopy at ambient temperature (Figure 6; for details, see Section S5 in the SI) and compared to the theoretical predictions. The UV-Vis spectrum of $\mathbf{1}$ in $\mathrm{CH}_{3} \mathrm{CN}$ featured two absorption maxima at $275 \mathrm{~nm}$ and $293 \mathrm{~nm}$ (Figure 6a), as predicted, while the absorption bands of both quinoxaline $\mathbf{2}$ and helicene $\mathbf{3}$ were substantially bathochromically shifted compared to their theoretical predictions by $50-100 \mathrm{~nm}$ presumably due to solvent effects (Figure $6 \mathrm{~b}-6 \mathrm{c}){ }^{38}$ Solvent effects can influence the properties of DAE systems by favoring CT relaxation as a competing process in $\mathrm{CH}_{3} \mathrm{CN}$, which is why the $\mathrm{UV}$-Vis spectra were further recorded in toluene to suppress this effect, resulting in comparable spectral characteristics (Figure 6). ${ }^{10,39}$ Having identified the spectroscopic signatures of the DAE systems in the open and the closed state, we performed UV-Vis and transient absorption spectroscopy measurements to monitor their interconversion upon irradiation.

\section{Figure 6}

Photocyclization Study. DAE systems 1-3 demonstrated different behavior upon irradiation of their solutions in either $\mathrm{CH}_{3} \mathrm{CN}$ or toluene at $300 \pm 20 \mathrm{~nm}$ with low intensity lamps in a Rayonet photoreactor (RMR600, 8 lamps of $8 \mathrm{~W})$.

UV-Vis spectra of DAE 1 (Figure 7a) featured a gradual disappearance of the absorption at $290 \mathrm{~nm}$ upon irradiation, accompanied by the appearance of the new absorption signal at $684 \mathrm{~nm}$ with a single isosbestic point at $500 \mathrm{~nm}$, indicative of photocyclization in accordance with the spectroscopic signature predictions (for details, see Section S4 in the SI). To our knowledge, this observation provides the first example of a photocyclization process for a DAE system implemented into a $6 \pi$ heteroaromatic six-membered ring. The photocyclization of DAE 1 was estimated to occur with a quantum yield of 0.12 in $\mathrm{CH}_{3} \mathrm{CN}$ and 0.25 in toluene (for details, see 
Section S6 in the SI), which is moderate compared to conventional DAE systems, likely as a result of the aromaticity of the bridge moiety. ${ }^{5,10}$ The photostationary state (PSS) was reached upon $30 \mathrm{sec}$ of irradiation (Figure 7a). However, the cyclized form 1-c was found to spontaneously undergo a reverse reaction even in the absence of light (thermal half-life $t_{1 / 2}=69 \mathrm{sec}$; Figure $7 \mathrm{~b}$ ), which prevented precise estimation of the composition in the PSS. Moreover, prolonged irradiation of 1 resulted in its apparent decomposition (for details see Figure S20, Section S5 in the SI). This unexpectedly short lifetime of 1-c is likely associated with its loss of aromaticity (as shown in Figure 3), as well as a significantly higher energy $\operatorname{HOMO}(\Delta E>1 \mathrm{eV})$ in the closed 1-c as compared to the open 1-o state (Figure 5a), which is not common for conventional DAE photoswitches. ${ }^{40-41}$

\section{Figure 7}

This unconventional orbital arrangement observed for $\mathbf{1}$ was altered in case of the extended aromatic quinoxaline-based DAE 2, with a HOMO orbital energy of both forms being energetically closer as compared to $\mathbf{1}$ (for details, see Section S7 in the SI). Irradiation of the quinoxaline-DAE 2 under the same conditions as pyrazine-DAE 1 did not lead to any observable changes in the UV-Vis spectra (for details, see Section S4 in the SI), suggesting the absence of photocyclization. Furthermore, prolonged irradiation of $\mathbf{2}$ by UV-Vis light resulted in decomposition of the compound (for details see Section S5, SI). On the contrary, irradiation of the solution of $\mathbf{3}$ in toluene at $350 \mathrm{~nm}$ resulted in the formation of additional signals with maxima at around $350 \mathrm{~nm}$ and $550 \mathrm{~nm}$ indicative of photocyclization (for details, see Section S4 in the SI), in agreement with the theoretical predictions. The PSS was reached after approximately 6 min (Figure $7 \mathrm{~d}$, inset) and the photocyclized form was stable over a period of several hours, unless further exposed to unfiltered visible light or higher temperatures. The sensitivity of $\mathbf{3}$ to prolonged 
light exposure was probed by transient absorption spectroscopy to find that a minor contribution of the triplet excited state competes with the photocyclization of $\mathbf{3}$ (for details, see Section S6 in the SI), accounting for the instability. The photocyclization of helicene-DAE 3 nonetheless occurred with a quantum yield of 0.25 in toluene, comparable to DAE 1, while featuring a longer lifetime of the photocyclized form.

To better understand of the processes governing the resistance of $\mathbf{2}$ to photocyclization in contrast to $\mathbf{1}$ and $\mathbf{3}$, we monitored their behavior in the excited state by transient absorption spectroscopy upon laser flash excitation at $355 \mathrm{~nm}$. It was found that an emerging absorption at $410 \mathrm{~nm}$ occurs upon laser flash excitation of $\mathbf{2}$, correlating very well with the quinoxaline intermediate triplet excited state. ${ }^{42-44}$ This was in accordance with a monoexponential decay of this absorbance on a $\mu \mathrm{s}$ scale (Figure 7c; for more details see Section S6 in the SI). However, the photocyclization of the majority of conventional diarylethene photoswitches was shown to occur without intersystem crossing. ${ }^{10,40}$ In addition, stabilization of the twisted intermolecular charge transfer (TICT) states can be a possible explanation for inhibited photocyclization. ${ }^{10}$ Moreover, the loss of aromaticity upon cyclization, as evidenced by the NICS $(1)_{\pi z z}$ calculations (Figure 3; for further details, see Section S7 in the SI), is expected to play a role in disfavoring the photocyclization of $\mathbf{2}$, rendering the reverse opening reaction more likely. The enhanced photocyclization ability was in accordance with the predictions based on the NICS $(1)_{\pi z Z}$ calculations, with a value suggesting lower (unfavorable) paratropic currents in cyclized $\mathbf{3}$ $\left(\mathrm{NICS}(1)_{\pi \mathrm{ZZ}}=20 \mathrm{ppm}\right)$ compared with $2\left(\mathrm{NICS}(1)_{\pi \mathrm{ZZ}}=30 \mathrm{ppm}\right)$, which did not display any photocyclization ability. Unlike $\mathbf{1}$ and $\mathbf{2}$ that lose all of their diatropic currents associated with aromaticity upon cyclization, $\mathbf{3}$ retains the diatropic currents within the adjacent aromatic rings that could account for its higher photocyclization capacity and suppression of the reverse reaction. 
This finding renders helicene 3 a unique example of a photochromic pyrazine-DAE system and reveals novel design opportunities towards aromatic DAE photoswitches.

\section{CONCLUSION}

This study presents a systematic evaluation of the photocyclization capacity of three novel pyrazine-based DAE systems $\mathbf{1}-\mathbf{3}$. The electronic structure and the geometry analysis based on cyclic and rotating disc voltammetry, UV-Vis and transient absorption spectroscopy, X-ray crystallography, as well DFT calculations, reveal key factors determining the tendency for photocyclization. A loss in aromaticity of the pyrazine-DAE systems was assumed to have a counteracting effect on the photocyclization ability. Effective photocyclization of pyrazine-DAE 1 was in accordance with the predictions of its lower aromaticity based on $\operatorname{NICS}(1)_{\pi Z Z}$ values, which were comparable to previously reported phenanthroline-DAE systems. This behavior was however accompanied with a short lifetime of the cyclized form, presumably as a result of the higher HOMO energy uncommon for conventional DAE switches, which led to two strategies to overcome this obstacle. Firstly, the aromatic core was extended to form the quinoxaline-DAE system 2, resulting in smaller energetic differences in molecular orbital energy levels comparable to conventional DAEs, at the expense of increased aromaticity, triplet excited state stabilization, and inhibited photocyclization. Finally, the pyrazine system was altered through additional phenyl

ring anullation to form helicene-DAE system 3, rendering it photocyclizable. This finding provides a novel approach towards aromatic DAE photoswitches that are potentially chiral of interest to the design of light-controlled nanotechnologies and possibly chiroptical photoswitches in the future.

\section{EXPERIMENTAL}


General Information. Synthesis of compounds 1-3 was performed by using precursors 7-9 that were prepared according to the literature procedures and 2,5-thiophene, 2,3-difluoro- 5,6-diamine, and 1,2-ethyldiamine, which are commercially available. The details of the synthetic procedure and characterization of the compounds are described in the Supporting Information, along with the spectroscopic analysis and DFT calculations of the reported systems.

\section{ASSOCIATED CONTENT}

Supporting Information. Synthesis, NMR Spectroscopy, Crystal Structure Data, Electrochemistry, UV-Vis Spectroscopy, Laser Flash Photolysis and Transient Absorption Spectroscopy, DFT Calculations. The Supporting Information is available free of charge on the ACS Publications website. (PDF)

\section{AUTHOR INFORMATION}

\section{Corresponding Author}

*diederich@org.chem.ethz.ch.

\section{Author Contributions}

The manuscript was written by J.M., C.S., and F.D. through contributions of all authors. J.M. conceptualized and designed the study. J.M. and C.S. performed DFT calculations and photoswitching studies. Synthesis was accomplished by J.M., N.H., J.C. (supervision), F.I., and S.E. R.G-P. performed the NICS $_{\pi z Z}$ calculations, N.T. the X-ray crystallographic analysis, and D.N. and G.G. the transient absorption spectroscopy (laser flash photolysis). R.L. and C.B. conducted the electrochemical measurements. F.D. supervised the study. All authors discussed the results and commented on the study. 


\section{Funding Sources}

This work was supported by the Swiss National Science Foundation Grant 200020_159802 and Agence National de la Recherche Fund 12-BS07-0004-METALHEL-01.

\section{Notes}

The authors declare no competing financial interest.

\section{ACKNOWLEDGMENT}

The authors are grateful to Dr. Michael Solar (ETH Zurich) for performing the X-ray crystallographic analysis, and to Dr. Mark Olivier Ebert, René Arnold, and Stephen Burkhardt (ETH Zurich) for help in NMR spectroscopy. Dr. Bruno Bernet (ETH Zurich) is acknowledged for proofreading the manuscript, and Mark Samame Hardmeier and Massimiliano Menichelli (ETH Zurich) for helpful discussions and technical support. J.C. is grateful to Etienne Gauthier for technical support. N.H. acknowledges the Agence National de la Recherche for funding (12-BS070004-METALHEL-01).

\section{ABBREVIATIONS}

ASE aromatic stabilization energy; DAE diarylethene; NICS nuclei independent chemical shifts; GIAO gauge-including atomic orbital; PSS photostationary state; PCM polarizable continuum model; HOMO highest occupied molecular orbital; LUMO lowest unoccupied molecular orbital.

\section{REFERENCES}

(1) Zheng, Y. B.; Hao, Q.; Yang, Y.-W.; Kiraly, B.; Chiang, I-K.; Huang, T. J. Light-Driven Artificial Molecular Machines. J. Nanophoton. 2010, 4, 042501. 
(2) Feringa, B. L.; Browne W. R. (Eds.) Molecular Switches; 2nd Ed., Vols. 1 and 2, Wiley VCH: Weinheim, Germany, 2011.

(3) Szymański, W.; Beierle, J. M.; Kistemaker, H. A. V.; Velema, W. A.; Feringa, B. L. Reversible Photocontrol of Biological Systems by the Incorporation of Molecular Photoswitches. Chem. Rev. 2013, 113, 6114-6178.

(4) Yagai, S.; Iwai, K.; Yamauchi, M.; Karatsu, T.; Kitamura, A.; Uemura, S.; Morimoto, M.; Wang, H.; Würthner, F. Photocontrol Over Self-Assembled Nanostructures of $\pi-\pi$ Stacked Dyes Supported by the Parallel Conformer of Diarylethene. Angew. Chem., Int. Ed. 2014, 53, 26022606.

(5) Irie, M. Diarylethenes for Memories and Switches. Chem. Rev. 2000, 100, 1685-1716.

(6) Irie, M.; Morimoto, M. Photoswitchable Turn-On Mode Fluorescent Diarylethenes: Strategies for Controlling the Switching Response. Bull. Chem. Soc. Jpn. 2018, 91, 237-250.

(7) Blanco, V.; Leigh, D. A.; Marcos, V. Artificial Switchable Catalysts. Chem. Soc. Rev. 2015, $44,5341-5370$.

(8) Sumi, T.; Kaburagi, T.; Morimoto, M.; Une, K.; Sotome, H.; Ito, S.; Miyasaka, H.; Irie, M. Fluorescent Photochromic Diarylethene That Turns on with Visible Light. Org. Lett. 2015, 18, 4802-4805.

(9) Hayakawa, R.; Higashiguchi, K.; Matsuda, K.; Chikyow, T.; Wakayama, Y. Optically and Electrically Driven Organic Thin Film Transistors with Diarylethene Photochromic Channel Layers. ACS Appl. Mater. Interfaces 2013, 5, 3625-3630. 
(10) Irie, M.; Fukaminato, T.; Matsuda, K.; Kobatake, S. Photochromism of Diarylethene Molecules and Crystals: Memories, Switches, and Actuators. Chem. Rev. 2014, 114, 1217412277.

(11) Herder, M.; Schmidt, B. M.; Grubert, L.; Pätzel, M.; Schwarz, J.; Hecht, S. Improving the Fatigue Resistance of Diarylethene Switches. J. Am. Chem. Soc. 2015, 137, 2738-2747.

(12) Milek, M.; Witt, A.; Streb, C.; Heinemann, F. W.; Khusniyarov, M. M. Tetraanionic $\mathrm{N}_{2} \mathrm{O}_{2}-$ Coordinating Ligands as Potential Building Blocks for Supramolecular Magnetic Networks. Dalton Trans. 2013, 42, 5237-5241.

(13) Walko, M.; Feringa, B. L. The Isolation and Photochemistry of Individual Atropisomers of Photochromic Diarylethenes. Chem. Commun. 2007, 1745-1747.

(14) Yam, V. W.-W.; Ko, C.-C.; Zhu, N. Photochromic and Luminescence Switching Properties of a Versatile Diarylethene-Containing 1,10-Phenanthroline Ligand and Its Rhenium(I) Complex. J. Am. Chem. Soc. 2004, 126, 12734-12735.

(15) Milek, M.; Heinemann, F. W.; Khusniyarov, M. M. Spin Crossover Meets Diarylethenes: Efficient Photoswitching of Magnetic Properties in Solution at Room Temperature. Inorg. Chem. 2013, 52, 11585-11592.

(16) Harada, A.; Takashima, Y.; Nakahata, M. Supramolecular Polymeric Materials via Cyclodextrin-Guest Interactions. Acc. Chem. Res. 2014, 47, 2128-2140.

(17) Sud, D.; Wigglesworth, T. J.; Branda, N. R. Creating a Reactive Enediyne by Using Visible Light: Photocontrol of the Bergman Cyclization. Angew. Chem., Int. Ed. 2007, 46, 8017-8019. 
(18) Chen, Z.; Niu, L.; Cheng, Y.; Zhou, X.; Zhong, C.; Zhang, F. Octathienyl/PhenylSubstituted Zinc Phthalocyanines J-Aggregated Through Conformational Planarization. Dalton Trans. 2011, 40, 393-401.

(19) Meng, X.; Zhu, W.; Zhang, Q.; Feng, Y.; Tan, W.; Tian, H. Novel Bisthienylethenes Containing Naphthalimide as the Center Ethene Bridge: Photochromism and Solvatochromism for Combined NOR and INHIBIT Logic Gates. J. Phys. Chem. B 2008, 112, 15636-15645.

(20) Zhu, W.; Song, L.; Yang, Y.; Tian, H. Novel Bisthienylethene Containing FerrocenylSubstituted Naphthalimide: a Photo- and Redox Multi-Addressable Molecular Switch. Chem. Eur. J. 2012, 18, 13388-13394.

(21) Zhang, Q.; Li, J.; Niu, L.; Chen, Z.; Yang, L.; Zhang, S.; Cao, L.; Zhang, F. A Rapid Response Photochromic Diarylethene Material for Rewritable Holographic Data Storage. Chin. Sci. Bull. 2013, 58, 74-78.

(22) Patel, D. G.; Walton, I. M.; Cox, J. M.; Gleason, C. J.; Butzer, D. R.; Benedict, J. B. Photoresponsive Porous Materials: the Design and Synthesis of Photochromic Diarylethene-Based Linkers and a Metal-Organic Framework. Chem. Commun. 2014, 50, 2653-2656.

(23) Rösner, B.; Milek, M.; Witt, A.; Gobaut, B.; Torelli, P.; Fink, R. H.; Khusniyarov, M. M. Reversible Photoswitching of a Spin-Crossover Molecular Complex in the Solid State at Room Temperature. Angew. Chem., Int. Ed. 2015, 54, 12976-12980.

(24) Feixas, F.; Matito, E.; Poater, J.; Solà, M. Quantifying Aromaticity with Electron Delocalisation Measures. Chem. Soc. Rev. 2015, 44, 6434-6451.

(25) Solà, M. Forty Years of Clar's Aromatic $\pi$-Sextet Rule. Front. Chem. 2013, 1, 1-8. 
(26) Portella, G.; Poater, J.; Solà, M. Assessment of Clar's Aromatic $\pi$-Sextet Rule by Means of PDI, NICS and HOMA Indicators of Local Aromaticity. J. Phys. Org. Chem. 2005, 18, 785791.

(27) Gershoni-Poranne, R.; Stanger, A. Magnetic Criteria of Aromaticity. Chem. Soc. Rev. 2015, 44, 6597-6615.

(28) Gershoni-Poranne, R.; Stanger, A., The NICS-XY-Scan: Identification of Local and Global Ring Currents in Multi-Ring Systems. Chem. -Eur. J. 2014, 20, 5673-5688.

(29) Stanger, A. Nucleus-Independent Chemical Shifts (NICS): Distance Dependence and Revised Criteria for Aromaticity and Antiaromaticity. J. Org. Chem. 2006, 71, 883-893.

(30) Stanger, A. Obtaining Relative Induced Ring Currents Quantitatively from NICS. J. Org. Chem. 2010, 75, 2281-2288.

(31) Hellou, N.; Srebro-Hooper, M.; Favereau, L.; Zinna, F.; Caytan, E.; Toupet, L.; Dorcet, V.; Jean, M.; Vanthuyne, N.; Williams, J. A. G.; et al. Enantiopure Cycloiridiated Complexes Bearing a Pentahelicenic N-Heterocyclic Carbene and Displaying Long-Lived Circularly Polarized Phosphorescence. Angew. Chem., Int. Ed. 2017, 56, 8236-8239.

(32) Neilson, B. M.; Lynch, V. M.; Bielawski, C. W. Photoswitchable N-Heterocyclic Carbenes: Using Light to Modulate Electron-Donating Properties. Angew. Chem., Int. Ed. 2011, $50,10322-10326$.

(33) Foresman, J. B.; Frisch, A. Exploring Chemistry with Electronic Structure Methods, 2nd Ed., Gaussian, Inc.: Pittsburg, 1995. 
(34) Frisch, M. J.; Trucks, G. W.; Schlegel, H. B.; Scuseria, G. E.; Robb, M. A.; Cheeseman, J. R.; Scalmani, G.; Barone, V.; Mennucci, B.; Petersson, G. A.; et al. Gaussian 09, Revision A.1; Gaussian, Inc.: Wallingford, CT, 2009.

(35) Castellanos, S.; Grubert, L.; Stößer, R.; Hecht, S. Diarylethene Photoswitches Featuring Tetrathiafulvalene-Containing Aryl Units. J. Phys. Chem. C 2013, 117, 23529-23538.

(36) Lee, B.-L.; Yamamoto, T. Syntheses of New Alternating CT-Type Copolymers of Thiophene and Pyrido[3,4-b]pyrazine Units: Their Optical and Electrochemical Properties in Comparison with Similar CT Copolymers of Thiophene with Pyridine and Quinoxaline. Macromolecules 1999, 32, 1375-1382.

(37) Connelly, N. G.; Geiger, W. E. Chemical Redox Agents for Organometallic Chemistry. Chem. Rev. 1996, 96, 877-910.

(38) Tapia, O.; Bertrán, J. (Eds.) Solvent Effects and Chemical Reactivity; Kluwer Academic Publishers: New York, USA, 2002.

(39) Irie, M.; Sayo, K. Solvent Effects on the Photochromic Reactions of Diaryiethene Derivatives. J. Phys. Chem. 1992, 96, 7671-7674.

(40) Staykov, A.; Yoshizawa, K. Photochemical Reversibility of Ring-Closing and RingOpening Reactions in Diarylperfluorocyclopentenes. J. Phys. Chem. C 2009, 113, 3826-3834.

(41) Staykov, A.; Areephong, J.; R Browne, W.; Feringa, B. L.; Yoshizawa, K. Electrochemical and Photochemical Cyclization and Cycloreversion of Diarylethenes and Diarylethene-Capped Sexithiophene Wires. ACS Nano 2011, 5, 1165-1178. 
(42) Pan, Y.; Sheng, Z.; Ye, X.; Ao, Z.; Chu, G.; Dai, J.; Yu, S. Photochemistry of Quinoxaline

Derivatives and Mechanism of the Triplet State Quenching by Electron-Poor Alkenes. $J$. Photochem. Photobiol. A: Chemistry 2005, 174, 98-105.

(43) Mac, M.; Danel, A.; Wisła, A.; Karocki, A.; Królicki, R. Electron Transfer and Intersystem Crossing Processes in New Dyes Based on 1H-Pyrazolo[3,4-b]Quinoxaline. J. Photochem. Photobiol. A: Chemistry 2006, 180, 88-100.

(44) Jia, H.; Schmid, B.; Liu, S.-X.; Jaggi, M.; Monbaron, P.; Bhosale, S. V.; Rivadehi, S.; Langford, S. J.; Sanguinet, L.; Levillain, E.; et al. Tetrathiafulvalene-Fused Porphyrins via Quinoxaline Linkers: Symmetric and Asymmetric Donor-Acceptor Systems. ChemPhysChem 2012, 13, 3370-3382. 
a)

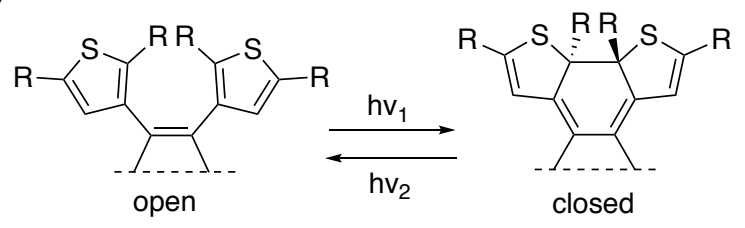

b)
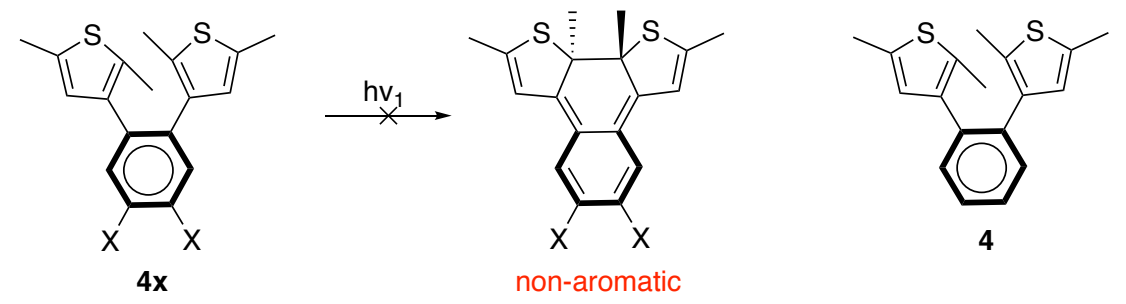

c)
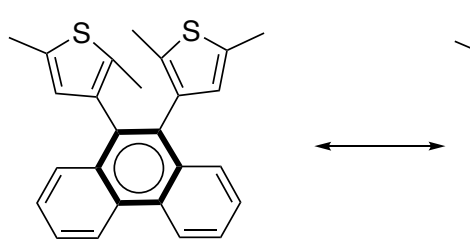

5

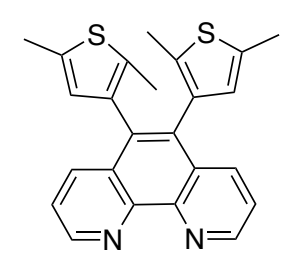

6
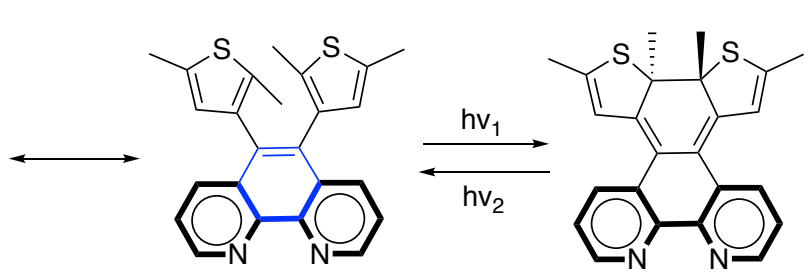

pseudoaromatic

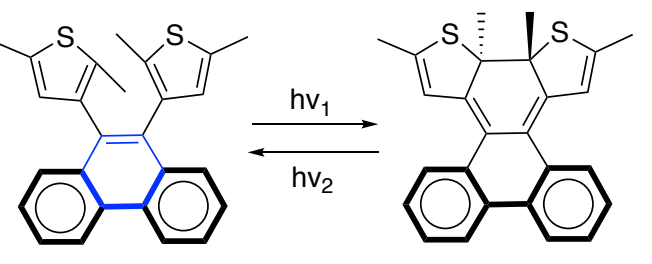

pseudoaromatic

Scheme 1. (a) Switching modes of diarylethene (DAE) photoswitches. (b) Structure of a phenylDAE system $\mathbf{4}$ comprising the core of the $\mathbf{4} \mathbf{x}$ systems reported by Khusniyarov et al. ${ }^{12}\left(\mathrm{X}=\mathrm{NH}_{2}\right)$. The authors do not report on the photocyclization, presumably due to high aromaticity of the $\pi$ system. (c) Examples of functional DAE switches developed by Walko and Feringa $(\mathbf{5})^{13}$ and Yam et al. $(\mathbf{6})^{14}$ that consist of a central aromatic unit which mimics the olefinic linker.

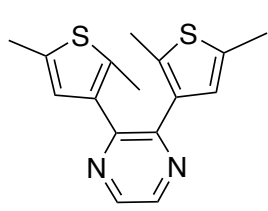

1

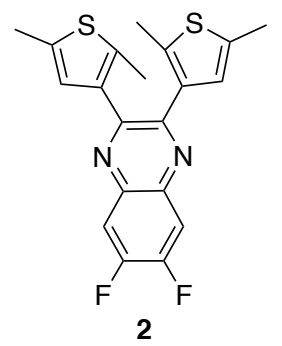

2

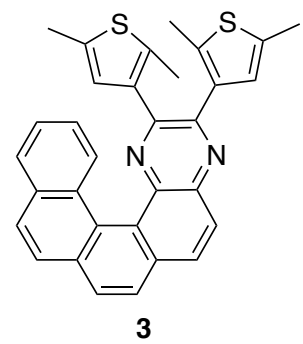

3

Figure 1. Structures of DAE systems employed in this study. 


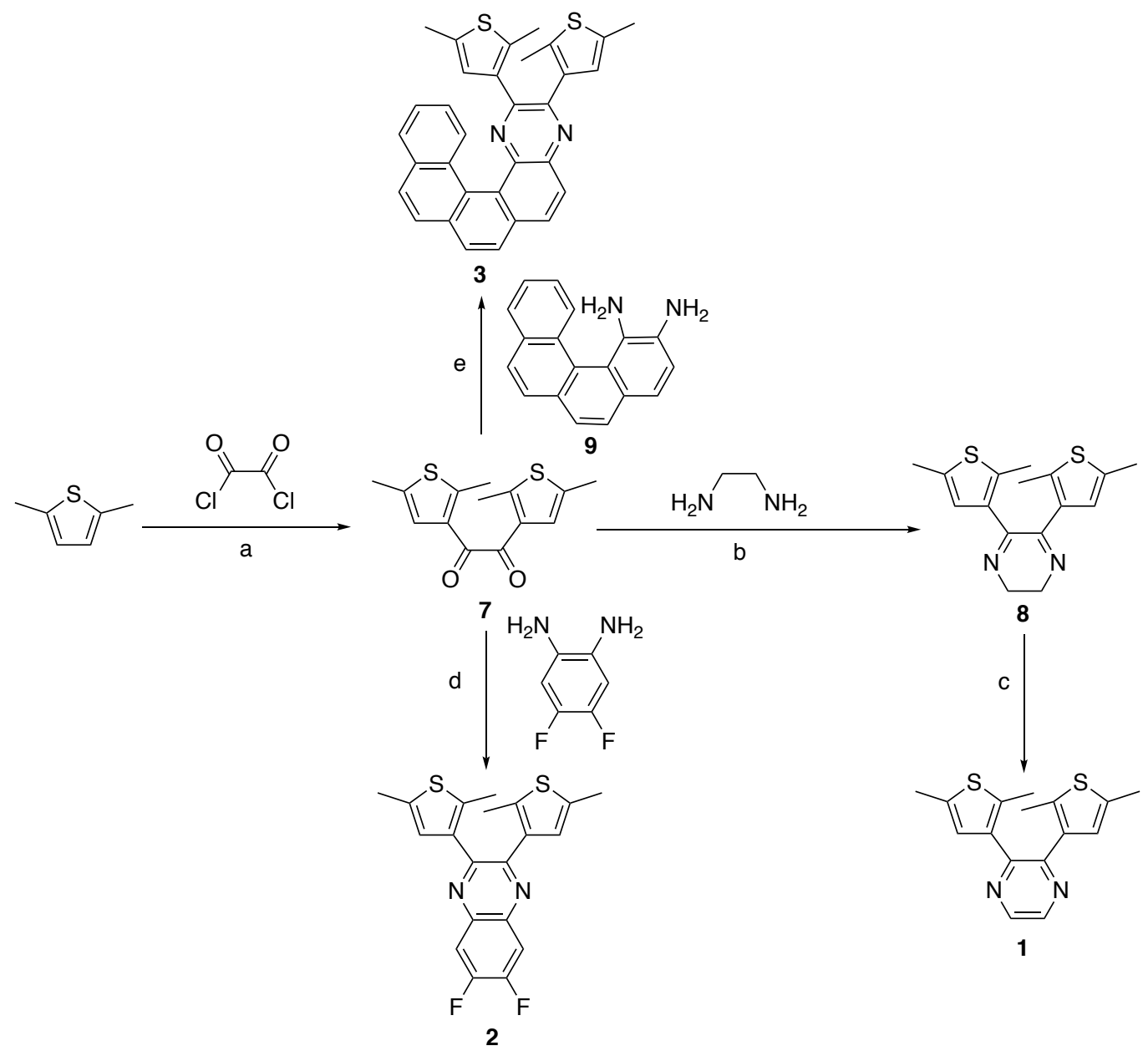

Scheme 2. Synthesis of DAE systems 1-3: (a) $\mathrm{AlCl}_{3}, \mathrm{Py}, \mathrm{CH}_{2} \mathrm{Cl}_{2},-18{ }^{\circ} \mathrm{C}, 2 \mathrm{~h}, 18 \%$ 7; (b) EtOH, air, $80{ }^{\circ} \mathrm{C}, 48$ h, $72 \%$ 8; (c) $\mathrm{KOH}$, air, EtOH, $80{ }^{\circ} \mathrm{C}, 1$ h, $98 \%$ 1; (d) EtOH, $80{ }^{\circ} \mathrm{C}, 12$ h, $98 \%$ 2; (e) 9, EtOH, $80^{\circ} \mathrm{C}, 12 \mathrm{~h}, 47 \%$ 3. Py $=$ pyridine. 


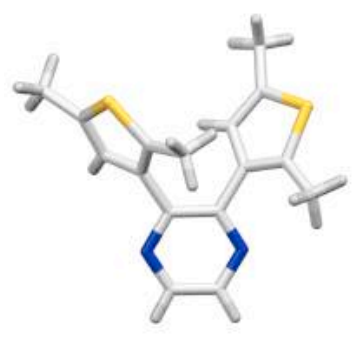

1

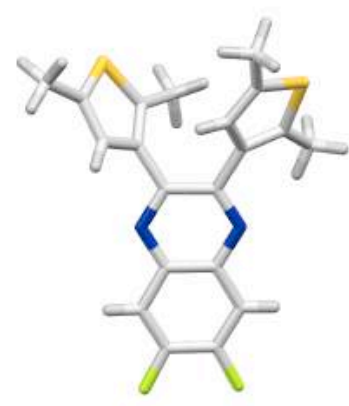

2

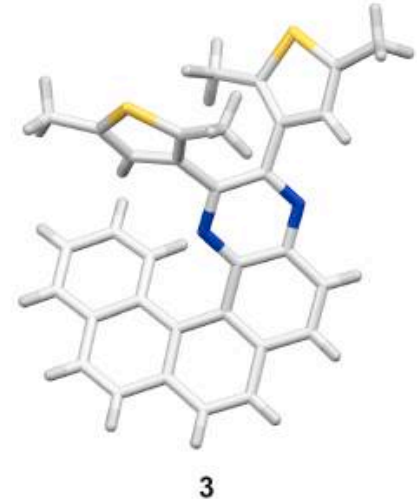

3

Figure 2. Small molecule crystal structures of DAE systems 1-2 in parallel conformation and $\mathbf{3}$ in antiparallel conformation, with space groups $P c a 2_{1}, P-1$, and $P 2_{1} / \mathrm{c}$, respectively (for details, see Section S3 in the SI). 
a)
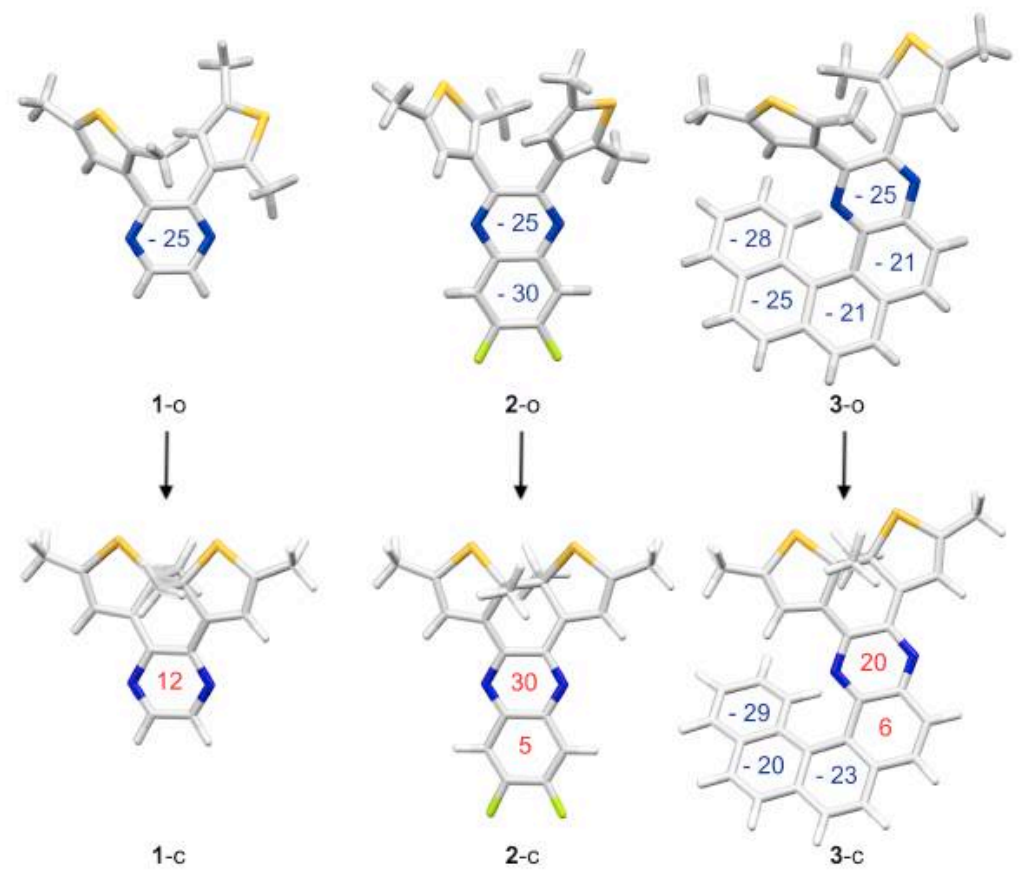

b)
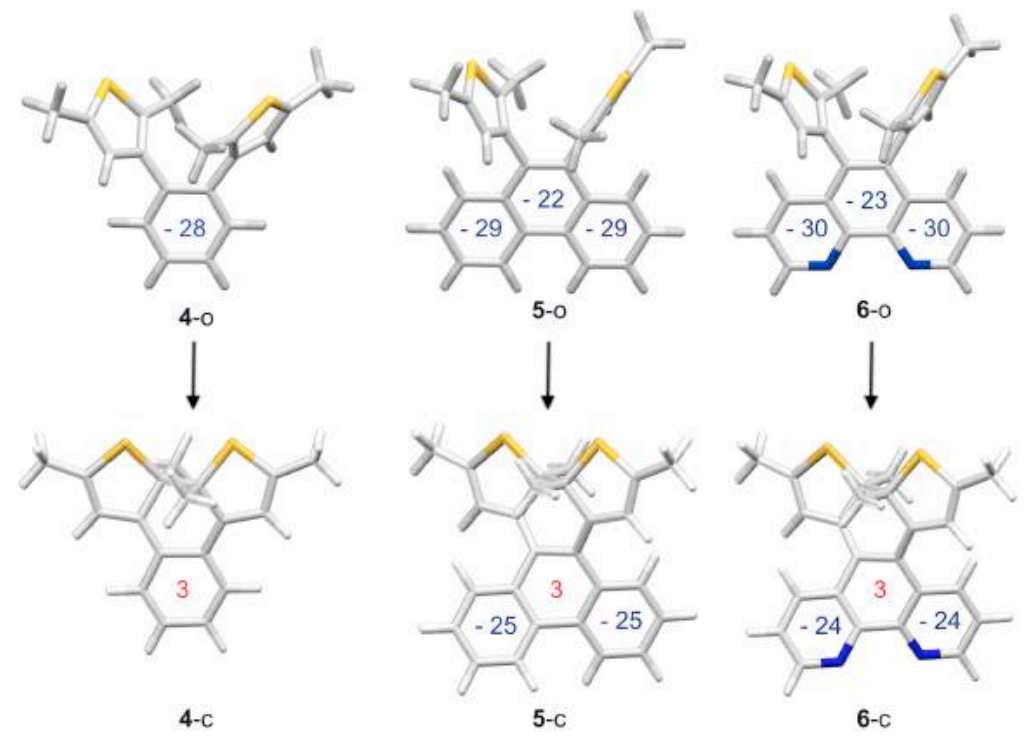

Figure 3. Optimized geometries (DFT B3LYP/6-31G(d)) of (a) systems 1-3 employed in this study and (b) representative DAE switches 4-6 based on those reported in the literature (13-15,33-34 $^{\text {in }}$ either open (-o, top; based on the crystal structure data, see Section S3 in the SI) or closed (-c; bottom) forms. NICS(1) $)_{\pi z}$ values $[\mathrm{ppm}]$ are shown within each respective ring (blue represents negative values indicating diatropic currents, while red refers to positive values indicating paratropic currents). For details, see Section S7 in the SI. 

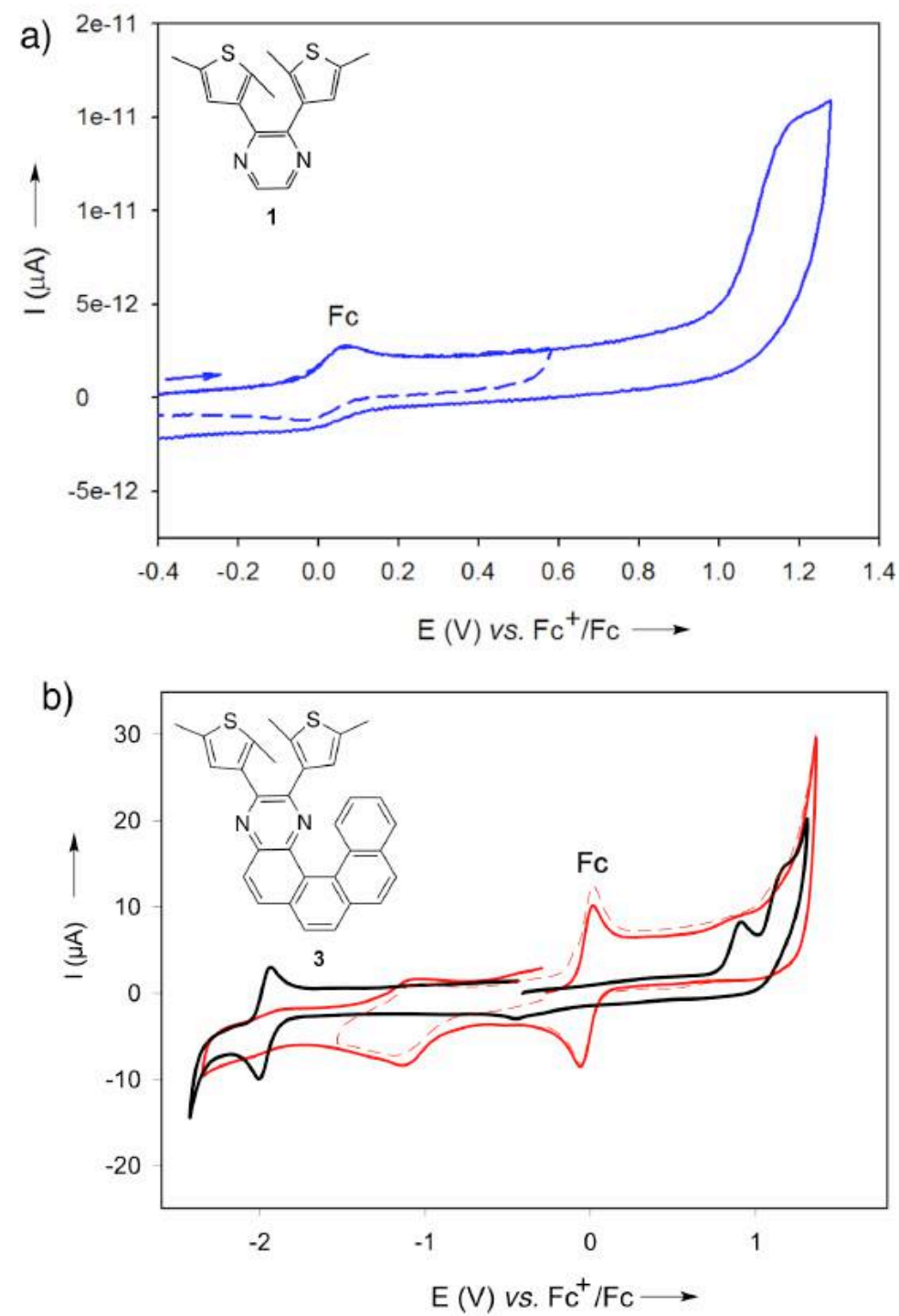

Figure 4. (a) Cyclic voltammetry of open-form 1 in $0.1 \mathrm{M} n-\mathrm{Bu}_{4} \mathrm{NBF}_{4} / \mathrm{CH}_{3} \mathrm{CN}$ on a GC electrode at a scan rate of $0.1 \mathrm{Vs}^{-1}$ in the presence of ferrocene $(\mathrm{Fc})$ as internal standard. (b) Cyclic voltammetry of 3 in $0.1 \mathrm{M} n-\mathrm{Bu}_{4} \mathrm{NBF}_{4} / \mathrm{CH}_{2} \mathrm{Cl}_{2}$ on a $\mathrm{GC}$ electrode at a scan rate of $0.1 \mathrm{Vs}^{-1}$ in the presence of ferrocene $(\mathrm{Fc})$ as internal standard before (black) and upon (red) irradiation. The redox interconversion of quinoxaline $\mathbf{2}$ is detailed within Section S4 in the SI. 
a)

a) $E(e V) \wedge$

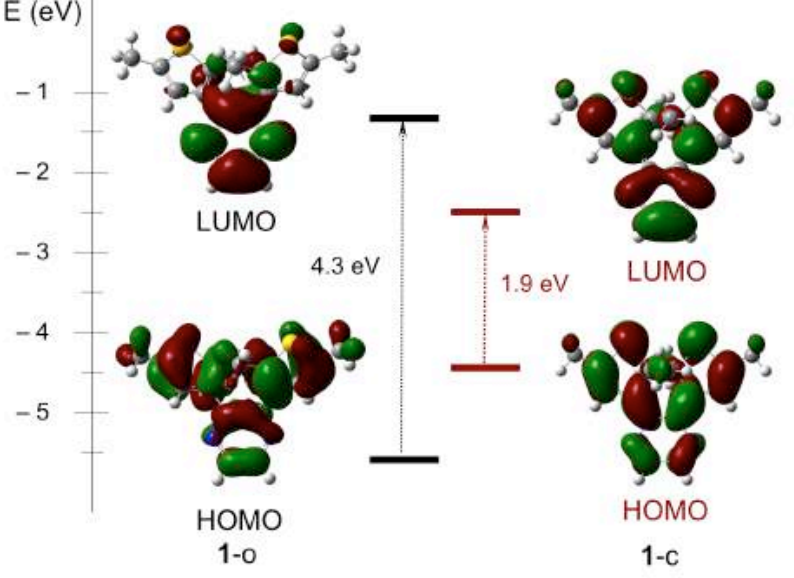

c)

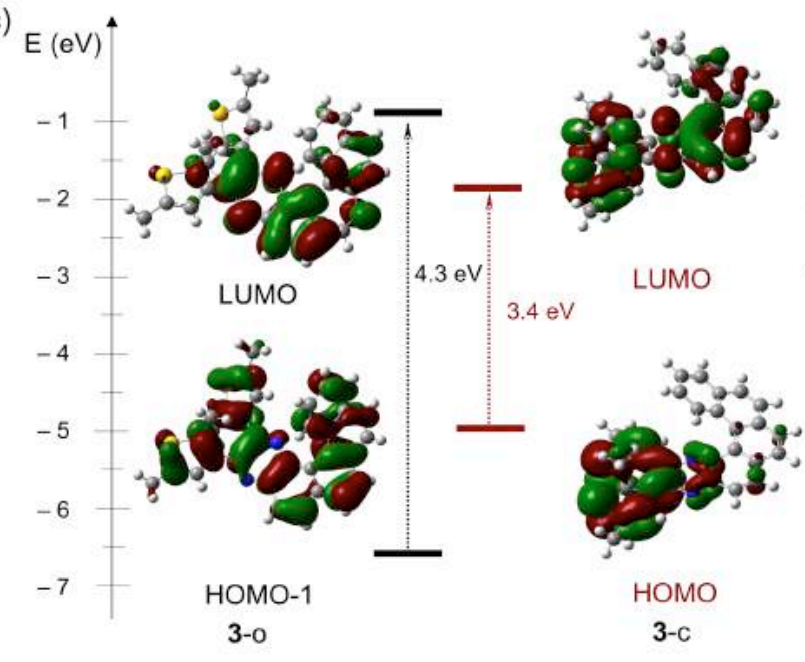

b)

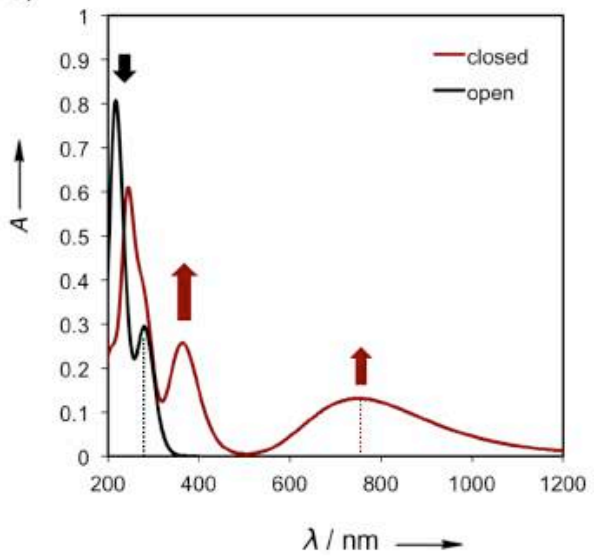

d)

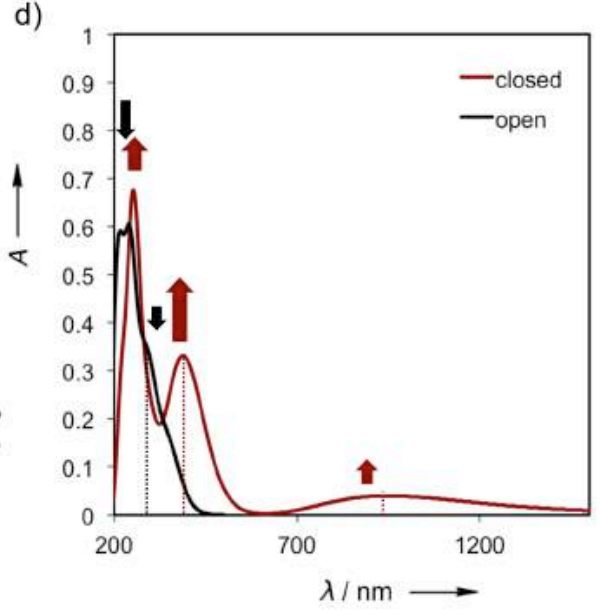

Figure 5. Calculated frontier molecular orbitals (FMO) (DFT:B3LYP/6-31G(d)) and UV-Vis spectra (TD-DFT:CAM-B3LYP/6-31G(d), number of states $=35, \mathrm{PCM}$ solvent $=\mathrm{CH}_{3} \mathrm{CN}$, toluene) of $\mathbf{1}$ and 3. (a) FMO of $\mathbf{1}$ in the open (1-o) and closed (1-c) states, with the corresponding (b) UV-Vis spectra in $\mathrm{CH}_{3} \mathrm{CN}$. (c) FMO of 3 in the open (3-o) and closed (3-c) states, with the corresponding (b) UV-Vis spectra in toluene. Decrease of the absorbance bands at $270-290 \mathrm{~nm}$ in the open states (black arrows) and appearance of new red-shifted absorption bands at $\lambda>500 \mathrm{~nm}$ (red arrows) in the UV-Vis spectra. For more details on the DFT calculations, please refer to the Section S7 in the SI. 

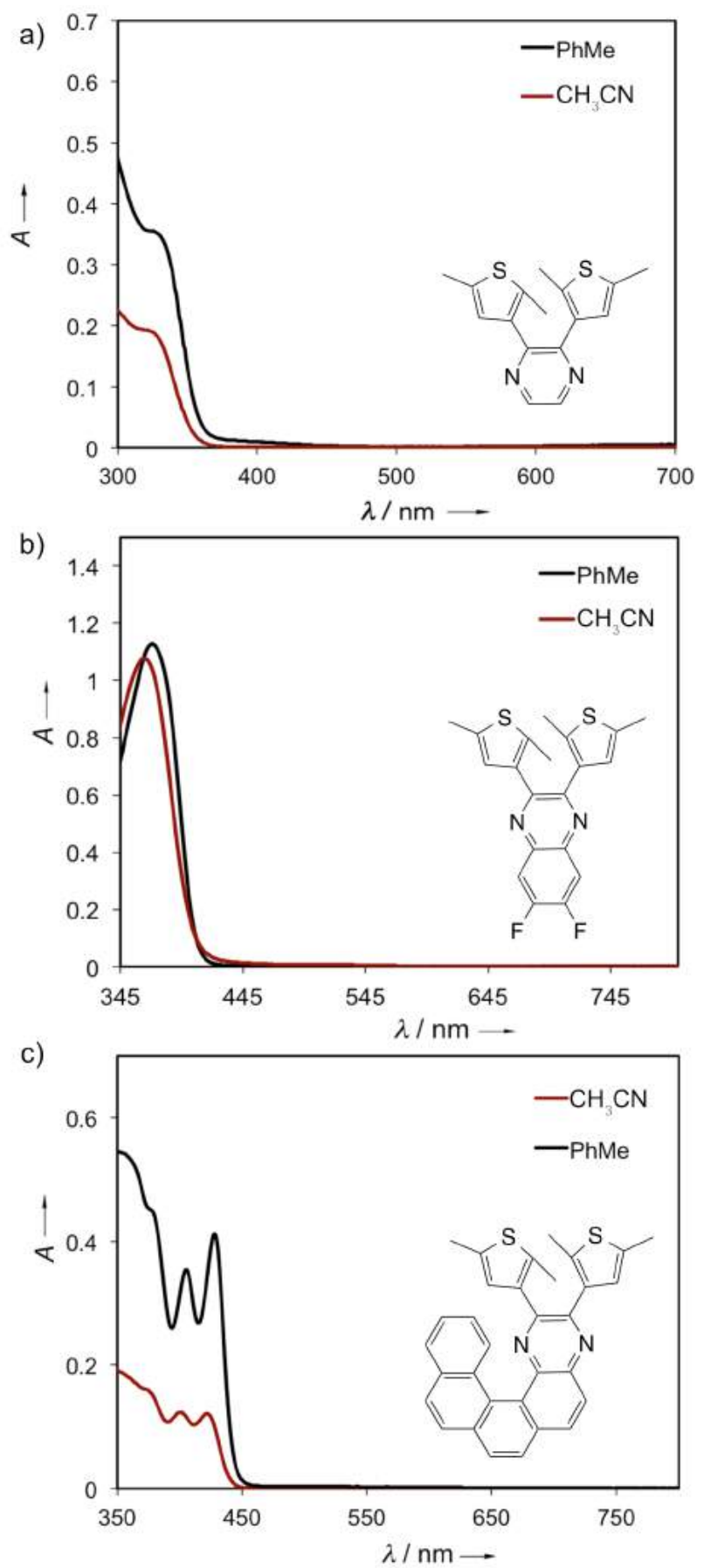

Figure 6. UV-Vis spectra in $\mathrm{CH}_{3} \mathrm{CN}$ (red) and PhMe (black) of DAE systems (a) 1, (b) 2, and (c) $3\left(\sim 10^{-5} \mathrm{M}\right)$ in the open form at ambient temperature. The extinction coefficients of the compounds are detailed within the Supporting Information (Section S5). 

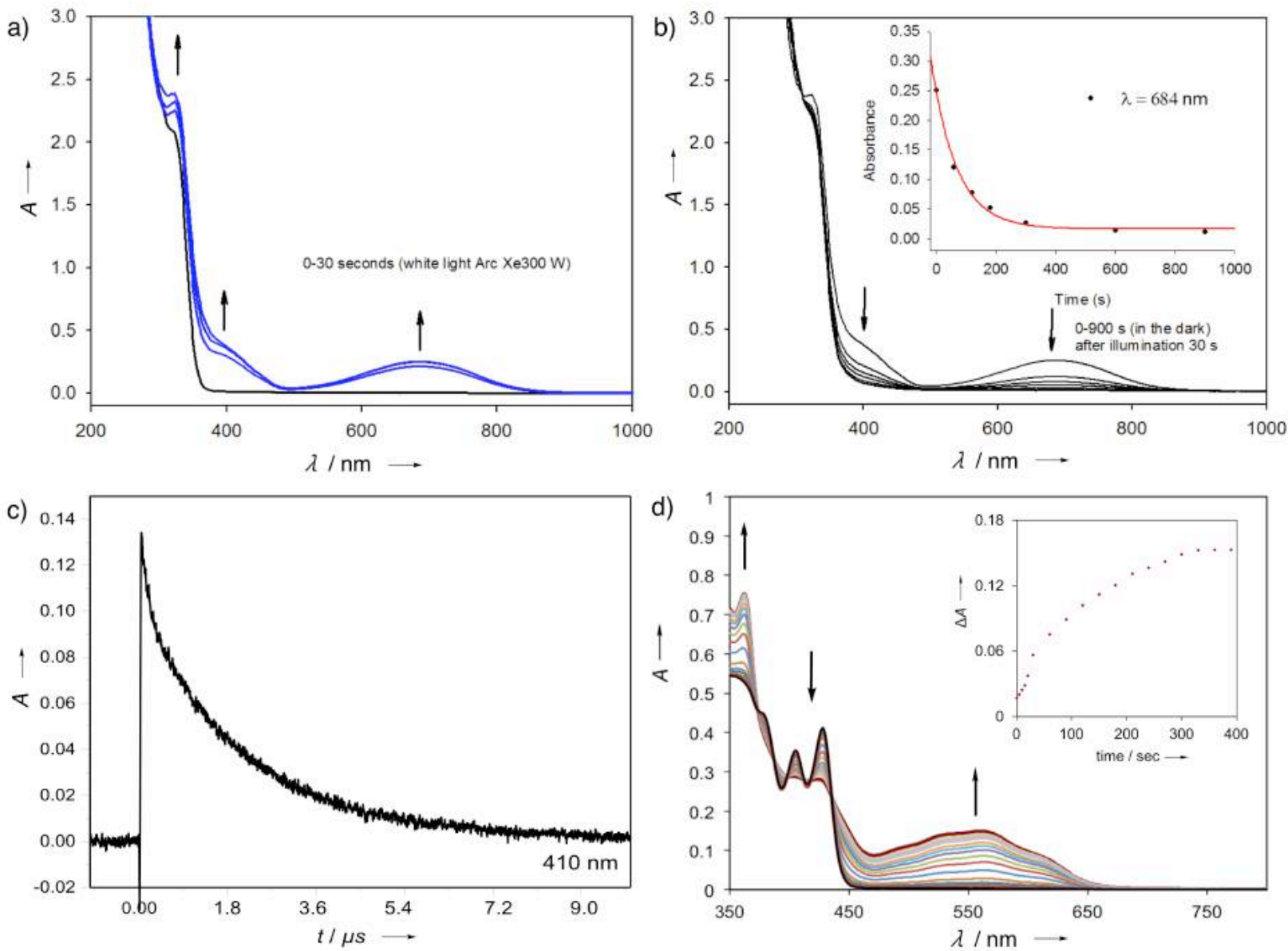

Figure 7. UV-Vis spectra of DAE $1\left(\sim 10^{-5} \mathrm{M}\right)$ in $\mathrm{CH}_{3} \mathrm{CN}$ at ambient temperature: (a) photocyclization by continuous white light illumination (Xe lamp, $300 \mathrm{~W}$; PSS after $30 \mathrm{sec}$ ); (b) reverse reaction in the dark (thermal half-life $t_{1 / 2}=69 \mathrm{sec}$ ). Photocyclization is revealed by the appearance of the new absorption bands at $400 \mathrm{~nm}$ and $643 \mathrm{~nm}$, which disappear upon exposure to white light. (c) Decay of the absorption at $290 \mathrm{~nm}$ of 2 after laser excitation at $355 \mathrm{~nm}$, which along with the decay at $410 \mathrm{~nm}$ (presented in Section S6 in the SI) confirms absence of photocyclization as a result of the excitation to a triplet state typical for quinoxaline systems. ${ }^{42-44}$ (d) UV-Vis spectra of DAE 3 in toluene at ambient temperature upon photocyclization by illumination at $350 \mathrm{~nm}$ (Rayonet RMR600, 8 lamps of $8 \mathrm{~W}$ ). Inset represents the evolution of the absorption at $550 \mathrm{~nm}$ over time until the PSS is reached. 
TOC GRAPHICS

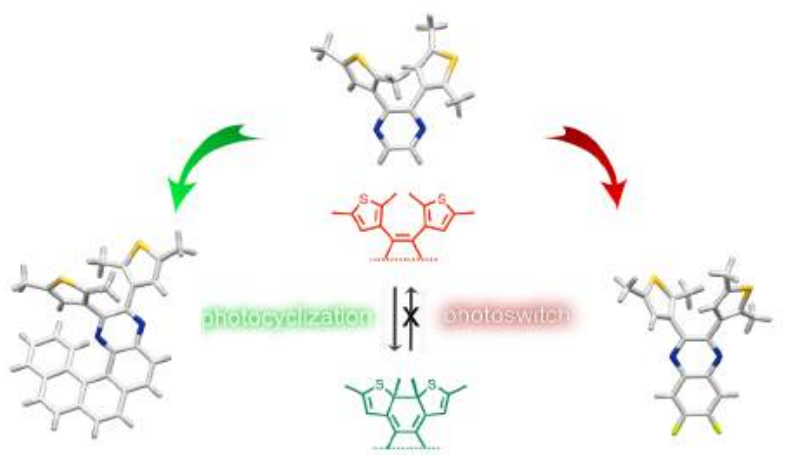

